\title{
Regeneración ósea guiada con injerto autógeno de mentón
}

Guided bone regeneration with autogenous graft of Chin

\section{Donald Ramos Perfecto ${ }^{1}$, John García Olivera' Luis Sueldo Gálvez ${ }^{1}$}

1 Estudiantes de la Segunda Especialidad en Periodoncia. Facultad Odontología UNMSM. Lima - Perú.

Correspondencia:

CD. Donald Ramos Perfecto Facultad Odontología, UNMSM

Av. Amezaga s/n, Lima, 1 Perú. Tlf: 6197000

e-mail: dramos_37@hotmail.com

\section{Resumen}

Las deficiencias de calidad ósea en el paciente, ya sea de ancho o de altura, hacen tomar decisiones al clínico, para mejorar dichas condiciones, con la finalidad de colocar implantes o mejorar rebordes deficientes que puedan soportar mejor un aparato protésico. Ante esto los procedimientos de regeneración ósea guiada con hueso propio (injerto autógeno) de mentón, son los de mayor pronóstico para la resolución del problema. En el presente, caso clínico mostramos el diagnóstico, la técnica quirúrgica, las ventajas y farmacoterapia del tratamiento de regeneración ósea guiada con injerto autógeno de mentón.

\begin{abstract}
The deficiencies of bone quality in the patient, either of wide or height, make the clinician take decisions to improve these conditions, with the purpose of placing implants or improving faulty edges that can support a prosthetics frame. For this, the procedures of guided bone regeneration with ones own chin bone (autogenous implant), are the ones with the best forecast for resolving the problem. In this clinical case we show the diagnosis, the surgical technique, the advantages and pharmacotherapy of guided bone regeneration treatment with autogenous chin implant.
\end{abstract}

Palabras clave: regeneración ósea, injerto autógeno, implante, periodoncia
Key words: bone regeneration, autogenous grat, implant, periodontics

\section{Introducción}

En la actualidad, la deficiencia de hueso nativo ya no es una contraindicación absoluta para la colocación de implantes, por lo cual gran parte del interés en la cirugía se ha centrado en la técnica de aumento de reborde. Existiendo diferentes técnicas y materiales para conseguir la regeneración ósea guiada, pero el "gold standard", vendría a ser el uso de injertos autógenos en cirugía reconstructiva de maxilares. ${ }^{1,2,3}$

Esto dependerá de muchos factores, como el tipo y la cantidad de hueso requerido, el acceso al área donante, morbilidad añadida por tener dos zonas quirúrgicas, así como también, la capacidad del cirujano y las preferencias o expectativas por parte del paciente ${ }^{4,5}$. Siendo una zona donante intraoral, de fácil acceso del mentón, con dimensiones máximas de injerto de $35 \mathrm{~mm}$ de largo, $4 \mathrm{~mm}$ de ancho y 10 mm de altura aproximadamente. ${ }^{6,7}$

Las características del mentón hacen que sean un material ideal para incrementar la dimensión transversal de la cresta alveolar, especialmente en el maxilar superior y en sectores posteriores de la mandíbula, más aún si se van a colocar implantes. ${ }^{8,9}$

Dentro de las ventajas biológicas podemos destacar lo siguiente:

1. Que el hueso medular le va a dar propiedades osteoinductoras, a su vez que la cortical del injerto sirve como una membrana biológica para dar propiedades osteoconductoras. 10,11

2. El hueso cortimembranoso se revasculariza más rápido que los injertos esponjosos de gran grosor. $^{12}$
3. Se presenta mayor concentración de proteínas morfogénicas óseas (BMPs), que permitan una mayor capacidad de regeneración ósea. ${ }^{13}$

4. El injerto de mentón en bloque posee una capacidad de reabsorción más lenta, en comparación con otros injertos autógenos, por lo que favorece la regeneración ósea a largo plazo. ${ }^{13,14}$

\section{Caso clínico}

Paciente de sexo femenino de 41 años de edad, de ocupación químico farmacéutica. Presenta prótesis fija en 1,1 y 2,1

Movilidad de 2,1, que al momento de retirar la corona se observó fractura coronaria total de dicha pieza.

Asintomático, con dolor leve a la percusión.

Sonrisa gingival

Edéntula parcial superior (Kennedy clase III) e inferior ausencia de 3,6 


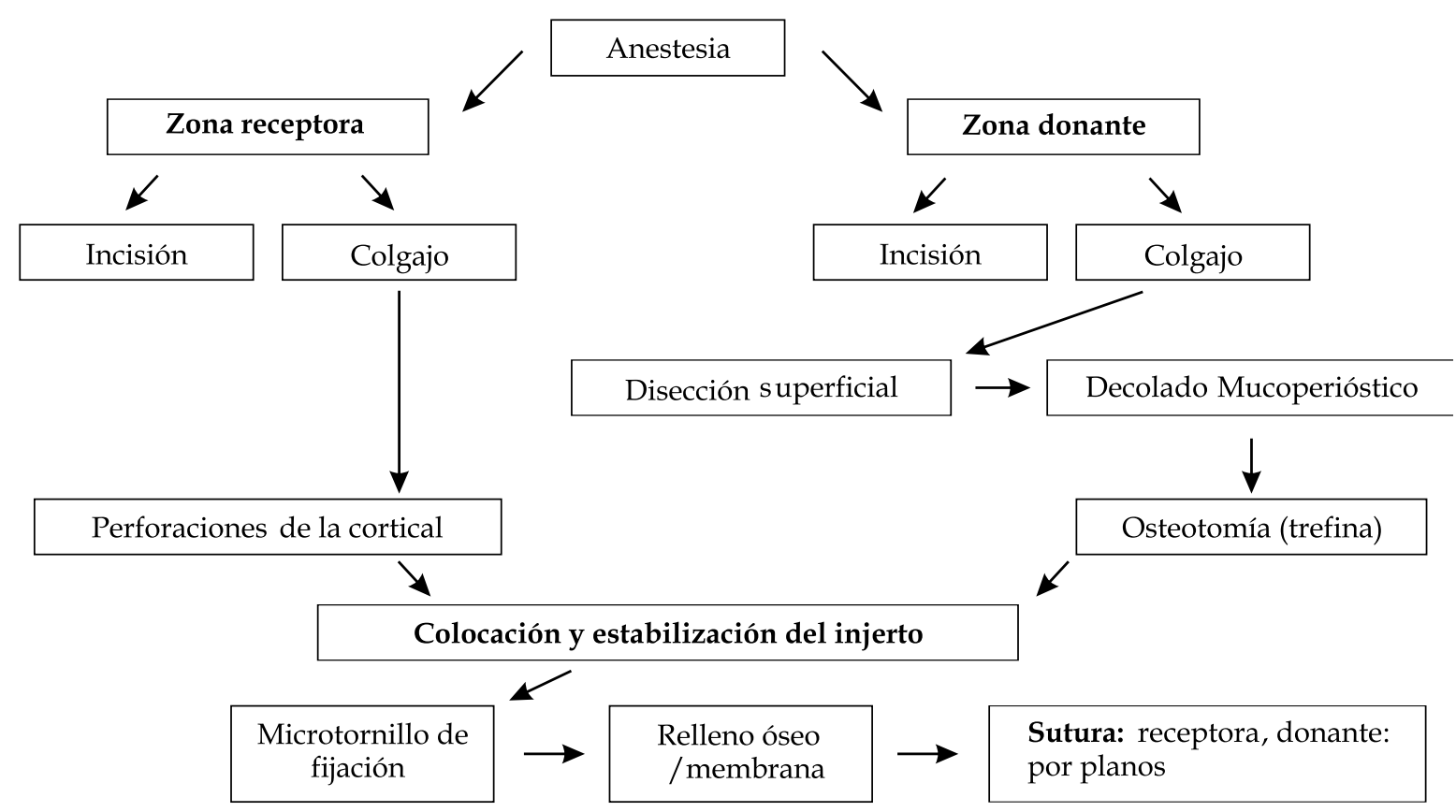

\section{Objetivos del tratamiento}

1. Mejorar la calidad ósea por medio de injertos autógenos.

2. Obtener un tejido óseo con las mejores condiciones biológicas.

3. Obtener un injerto óseo con un "gol standard" máximo para la colocación de implantes.

4. Disminuir la morbilidad causada por el acto quirúrgico y el proceso inflamatorio.

5. Obtener un mejor eje protésico previo a la colocación de implantes.

\section{Plan de tratamiento}

El tratamiento consistió en un procedimiento de regeneración ósea guiada con injerto autógeno de mentón en bloque utilizando una trefina quirúrgica tipo sacabocado. Con la utilización de materiales de relleno óseo y membrana reabsorbible de colágeno.

\section{Procedimiento clínico}

La tomografía, si bien es cierto nos brinda un diagnóstico más preciso de la cantidad ósea, necesaria para la colocación de implantes; hay casos en que este examen auxiliar puede no ser necesario, como en este caso. El paciente refiere que ha tenido un trau- ma en la pieza 2,1 hace cuatro meses, pero no recuerda si hubo hinchazón o supuración. Al examen clínico se observó una fractura coronaria; por lo que se decidió tomar una radiografía periapical con malla milimetrada para descartar alguna fractura o infección (Fig 1). Esto reveló una raíz corta con obturación endodóntica y con el ligamento periodontal ensanchado y relación corono raíz de 2,1, sin ninguna otra patología resaltante. Por lo que se planteó la posibilidad de realizar un implante inmediato, con el riesgo de tener un defecto óseo. El paciente acepta el tratamiento y firma el consentimiento respectivo.

Al extraer la pieza 2,1 se observó una fractura vertical radicular que no se había observado con la radiografía periapical (Fig 2) y un defecto óseo tipo dehiscencia que involucraba toda la tabla vestibular de la raíz 2,1. La medición del defecto registró un largo de 9 $\mathrm{mm}$, un ancho de $6 \mathrm{~mm}$ y una altura de $12 \mathrm{~mm}$. Utilizando un calibrador óseo se observó un grosor máximo de $4 \mathrm{~mm}$ en la zona media del lecho.

La colocación del implante en esas condiciones podría influir negativamente en la estabilidad primaria y en la estabilidad secundaría en un corto y largo plazo respectivamente. Además de alterar el eje protésico ideal del implante con el riesgo de existir una recesión gingival alterando la estética, por la exposición de las roscas del implante que en estos casos se presenta.

Tomando en cuenta las consideraciones antes mencionadas, se decidió realizar una regeneración ósea guiada con injerto autógeno de mentón en bloque.

Como parte del protocolo se tomó una radiografía panorámica, para decidir la ubicación del lecho donante, y un hemograma completo que incluyó tiempo de sangría y coagulación.

Luego de la asepsia y antisepsia intraoral y extraoral se procedió a la anestesia infiltrativa del lecho receptor, luego se continuó con una incisión crevicular desde mesial de las piezas 1,3 a 2,3, la que se realizó con hoja de bisturí $\mathrm{N}^{\mathrm{o}} 12$ por vestibular y palatino, con una incisión supracrestal realizada con hoja de bisturí $\mathrm{N}^{\circ} 15$ a nivel de la zona edéntula correspondiente a la pieza 2,1. Inmediatamente después se decoló por vestibular y palatino a espesor total.

Se confeccionó la plantilla según las dimensiones del defecto, que sirvió para extraer el bloque óseo (Fig. 3. 4.5.).

Luego se paso al lecho donante, colocando anestesia infiltrativa por vestibular desde distal de las piezas 4,3 y 3,3 eligiéndose la zona donante entre 
Fig. 1. Rx pre operatoria
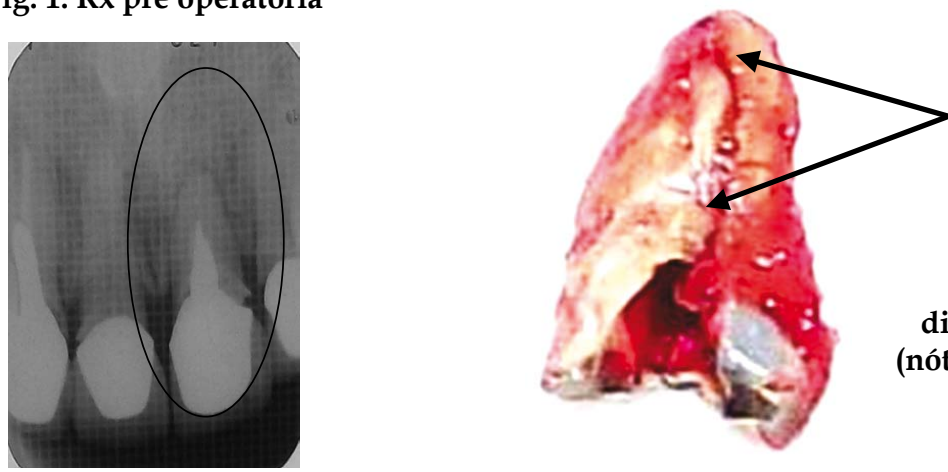

Fig. 2.

diente extraido

(nótese la fractura)

Fig. 3. 4. 5. Decolado y medicion del lecho receptor.y confección de la plantilla
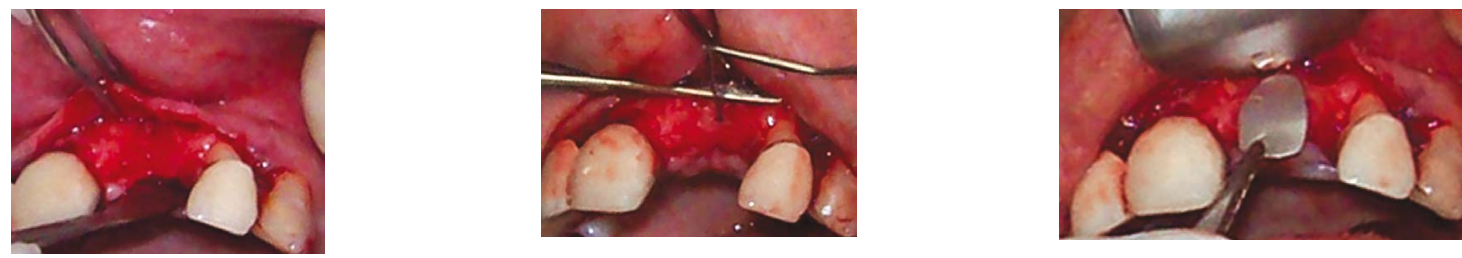

Fig. 6. 7. 8. Medición e incisión festoneada y decolado a espesor parcial con la respectiva medicion del lecho donante
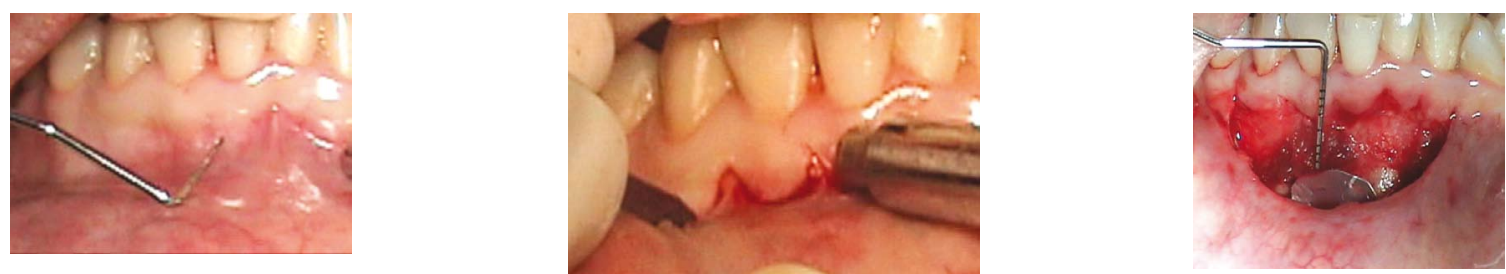

Fig. 9. 10. 11. 12. Utilización de la trefina de $10 \mathrm{~mm}$ con colocación del tornillo de fijación
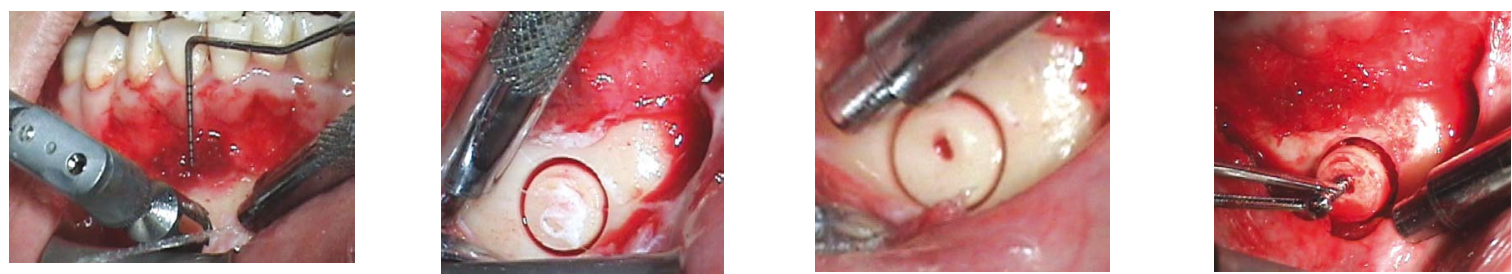

Fig. 13. 14. 15. 16. Colocación y fijación del injerto óseo en bloque de mentón en la zona receptora con la colocación de la membrana de colágeno.
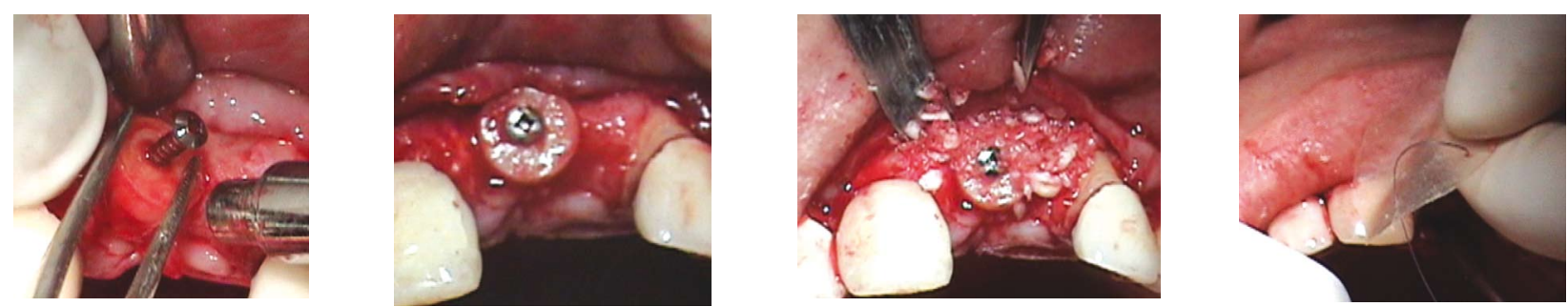

Fig. 17. 18. 19. Síntesis de tejidos en zona receptora y donante (por planos)

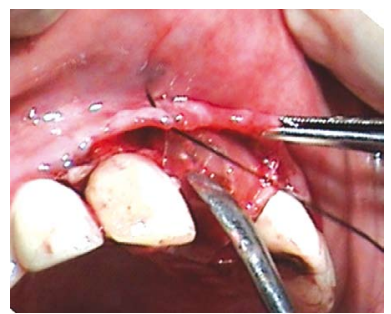

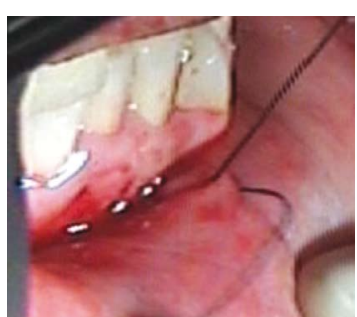

Post operatorio: 2 meses despuès

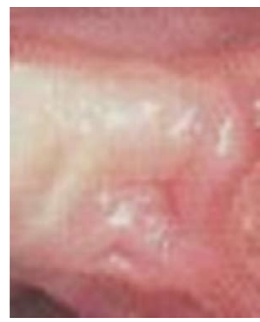


las piezas 4,3 y 4,1, según el informe de la radiografía panorámica.

Se procedió a realizar una incisión festoneada a 5 milímetros del margen gingival desde mesial de la pieza 3,3 hasta distal de 4,3 con una hoja de bisturí $\mathrm{N}^{\mathrm{o}} 15$ se realizó un decolado a espesor parcial. Se midió con una sonda periodontal el largo de la raíz de los incisivos, para realizar el decolado a espesor total y proceder a la obtención del bloque óseo (Fig 6. 7. 8.).

Luego con una trefina de $10 \mathrm{~mm}$ de diámetro se procedió a la trepanación de hueso mandibular con una profundidad de $4 \mathrm{~mm}$; rellenando el lecho con hidroxiapatita. Una vez obtenido el injerto y colocado su respectivo tornillo, se pasó a preparar la zona donante decorticalizándolo para lo cual se marcaron puntos sangrantes (Fig 9. 10. 11. 12.)

Inmediatamente después se colocó el injerto fijándolo con su respectivo tornillo de $1.5 \mathrm{~mm}$ por $10 \mathrm{~mm}$. Una vez estabilizado el injerto se empaquetó hueso halógeno desmineralizado seco y congelado, alrededor del injerto para llenar los espacios muertos que pudieran haber quedado. Luego se adaptó una membrana de colágeno al lecho para cubrir el injerto y generar una óptima regeneración (Fig. 13. 14 15. 16.). Finalmente se procedió a la síntesis de partes blandas, teniendo la particularidad de que a nivel mandibular se suturó por planos, para una mejor cicatrización y afrontamiento ideal del colgajo (Fig. 17. 18. 19.).

Farmacoterapia e indicaciones post operatorias : Clindamicina 300mg /6hr/10d; ketorolaco 60mg + Dexametasona 0,5mg / IM/2d; ibuprofeno $400 \mathrm{mg} / 8 \mathrm{hr} / 6 \mathrm{~d}$; hielo por $2 \mathrm{~h}$, descanso y dieta blanda.

\section{Discusión}

Si bien es cierto que la regeneración ósea guiada es un procedimiento predecible, tenemos que tener en cuenta la morbilidad del paciente, así como también el costo beneficio.

Cordaro ${ }^{1}$ y Simion ${ }^{3}$, realizaron éste procedimiento utilizando cincel y martillo, que genera un post operatorio donde la inflamación se exacerba y también afecta la ATM ya que los golpes pueden inflamar o producir dolor post cirugía. En comparación con dichos autores, la técnica de la trefina genera rapidez en el acto quirúrgico, y un post operatoria sin complicaciones.
Cabe resaltar que según Weber ${ }^{15}$ las complicaciones que se pueden generar son la posible infección, la exposición de la membrana, la exposición del injerto, y el rechazo del bloque.

En nuestro caso el post operatorio fue bien soportado por el paciente con un mínimo de inflamación, sólo se presentó un dolor de moderado a leve, que con los antiinflamatorios y analgésicos sistémicos fueron controlados.

En lo que respecta a la exposición de la membrana, se contrarrestó con dos incisiones verticales y divergentes por vestibular del lecho quirúrgico.

La infección fue controlada con clindamicina 24 horas antes, continuando después de la intervención quirúrgica.

El injerto se adaptó correctamente y se obtuvo estabilidad obteniendo un lecho bien vascularizado para prevenir el rechazo del tejido óseo.

\section{Conclusiones}

- El injerto es de fácil obtención, baja morbilidad y tiene una buena aceptación por parte del paciente.

- Es un procedimiento práctico y eficaz para aumento de la tabla vestibular

- Tiene limitaciones que derivan de su tamaño y de las características del hueso cortical.

- Escasa aplicabilidad en defectos verticales, relleno de cavidades.

- La técnica con trefina reduce el tiempo quirúrgico, el dolor post operatorio en la ATM, como también los signos y síntomas de inflamación.

\section{Referencias bibliográficas}

1. Cordaro L, Amade D, Cordaro M. Clinical results of alveolar ridge augmentation with mandibular block bone grafts in partially edentulous patients prior to implant placement. Clin Oral Impl Res 2002. 13:103-111.

2. D'addona A, Nowzari H. Intramembranous autogenous osseous transplants in aesthetic treatment of alveolar atrophy. Periodontol 2000. 2001. 27: 148-161.

3. Simion, M., Jovanovic, S.A., Trisi, P., Scarano, A. \& Piattelli, A. Vertical ridge augmentation around dental implants using a membrane technique and autogenous bone or allografts in humans. Int. J. Period Rest Dent 1998. 18:9-23.
4. Buser, D., Dula, K., Hirt, H.P. \& Schenk, R.K. Lateral ridge augmentation using autografts and barrier membranes: A clinical study with 40 partially edentulous patients. J Oral Maxil Surg. 1996. 54:420-432.

5. Lin KY, Bartlett SP, Yaremchuk MJ, Fallon M, Grossman RF, Whitaker LA. The effect of rigid fixation on the survival of onlay bone grafts: an experimental study. Plast Reconstr Surg 1990. 86:449-456.

6. Miller NA, Penaud J, Kohler C, Ambrosini P. Regeneration of bone graft donor sites. Clin Oral Impl Res 1999. 10:386-330

7. Raghoebar G, Liem R, Bos R, Van der Wal J, Vissink A. Resorbable screws for fixation of autologous bone grafts. Clin Oral Impl Res 2006. 17: 288-293.

8. Rompen, E. H., Biewer, R., Vanheusden, Zahedi, S. \& Nusgens, B. The influence of cortical perforations and of space filling with peripheral blood on the kinetics of guided bone regeneration. A comparative hystometric study. Clin Oral Impl Res 1999. 10:85-94.

9. Tinti, C. \& Parma-Benfenati, S. Vertical ridge augmentation: Surgical protocol and retrospective evaluation of 48 consecutively inserted implants. Int J Period Rest Dent 1998. 18:445-443.

10. Smolka W, Eggensperger N, Carollo $\mathrm{V}$, Ozdoba C, Iizuka T. Changes in the volume and density of calvarial split bone grafts after alveolar ridge augmentation. Clin Oral Impl Res 2006. 17:149-155.

11. Hunt, D.R. \& Jovanovic, S.A. Autogenous bone harvesting: a chin graft technique for particulate and monocortical bone blocks. Int J Period Rest Dent 1999. 19:165-173

12. Lang, N.P., Hammerle, C.H.F., Bragger, U., Lehmann, B. \& Nyman, S.R. Guided tissue regeneration in jawbone defects prior to implant placement. Clin Oral Impl Res 1994. 5:92-97.

13. Nevins, R. \& Mellonig, J.T. The advantage of localized ridge augmentation prior to implant placement: A two stage event. Int J Period Rest Dent 1994. 14:97-111.

14. Rominger, J.W. \& Triplett, R.G. The use of guided tissue regeneration to improve implant osseointegration. J Oral Max Fac Surg 1994. 52:106-112.

15. Weber H.P., Crohin C.C, Fiorellini J.P. A 5-year prospective clinical and radiographic study of non-submerged dental implants. Clin. Oral Impl. Res. 2000; 11:144-153.

Recibido: 10-11-2007

Aceptado para publicación: 25-11-2007 